\title{
PERBEDAAN PENDAPATAN PETANI PADI SAWAH ANTARA ETNIS LOKAL DAN NON LOKAL DI DAERAH IRIGASI SANGKUB KABUPATEN BOLAANG MONGONDOW UTARA
}

\author{
Mega Putri Kesek \\ Eyverson Ruauw \\ Melissa L.G. Tarore
}

\begin{abstract}
The purpose of this study to look at income differences between ethnic Local and Non Local of paddy rice farmers in Sangkub irrigated areas. This study took places in the village of Sangkub Two and Pangkusa Village, Sub-district of Sangkub, District of North Bolaang Mongondow. The study conducted from September to December 2016. Data collection is Primary and Secondary data. The primary data obtained through interviews using a questionnaire to 40 respondent farmers from two different ethnicities. They are 20 persons of Local ethnic and 20 persons of Non Local ethnic using simple random sampling method. Secondary data were obtained from the agencies concerned, namely the North Bolmong District Agriculture Office. The data collected in the study: (1) The characteristics of farmers, (2) Expenditures of the farmer (IDR), Income (IDR). Analysis of data used Analisys of Farm Income and Analysis of average difference by using t-test. The results showed that the income of farmers of paddy between ethnic Local and Non-Local is different where non-local ethnic incomes have higher incomes than the local ethnic.
\end{abstract}

Key words: income differences, paddy rice farmers, Local and Non-Local Non, Sub-district of Sangkub, North Bolaang Mongondow District

\begin{abstract}
ABSTRAK
Tujuan dari penelitian ini untuk melihat perbedaan pendapatan petani padi sawah antara etnis Lokal dan Non Lokal di daerah irigasi Sangkub. Penelitian ini bertempat di Desa Sangkub Dua dan Desa Pangkusa, Kecamatan Sangkub, Kabupaten Bolaang Mongondow Utara. Waktu penelitian dari bulan September sampai Desember 2016. Jenis data penelitian yaitu data Primer dan Sekunder. Data primer diperoleh melalui wawancara langsung menggunakan daftar pertanyaan (kuesioner) dengan 40 responden petani dari dua etnis yang berbeda yaitu 20 dari etnis Lokal dan 20 dari etnis Non Lokal dengan menggunakan metode Simple Random Sampling (sampel acak sederhana), sampel di ambil secara acak. Data sekunder diperoleh dari instansiinstansi terkait yaitu Dinas Pertanian Kabupaten Bolmong Utara. Adapun data yang dikumpulkan dalam penelitian yaitu (1) Karakteristik petani, (2) Pengeluaran yaitu biaya yang oodikeluarkan oleh petani (Rp), (3) Pendapatan (Rp). Analisis data menggunakan Analisis Pendapatan Usahatani dan Analisis Uji beda rata-rata dengan menggunakan Uji-t. Hasil penelitian menunjukkan bahwa pendapatan petani padi sawah antara etnis Lokal dan Non Lokal berbeda dimana pendapatan etnis non-lokal memiliki pendapatan lebih tinggi dari pada etnis lokal.
\end{abstract}

Kata kunci: perbedaan pendapatan, petani padi sawah, lokal dan sukubangsa Lokal dan Nonlokal, Kecamatan Sangkub, Kabupaten Bolaang Mongondow Utara 


\section{PENDAHULUAN}

Pada umumnya pembangunan ekonomi diartikan sebagai serangkaian usaha dalam suatu perekonomian untuk mengembangkan kegiatan ekonominya sehingga infrastruktur lebih banyak tersedia, perusahaan semakin banyak dan berkembang, taraf pendidikan semakin tinggi dan teknologi semakin meningkat. Sebagai implikasi dari perkembangan ini kesempatan kerja akan bertambah, tingkat pendapatan meningkat dan kemakmuran masyarakat menjadi semakin tinggi (Sukirno, 2010)

Setiap daerah mempunyai corak pertumbuhan ekonomi yang berbeda dengan daerah lain. Perencanaan pembangunan ekonomi suatu daerah pertama-tama perlu mengenali karakter ekonomi, sosial dan fisik daerah itu sendiri, termasuk interaksinya dengan daerah lain. Tidak ada strategi pembangunan ekonomi daerah yang dapat berlaku untuk semua daerah. (Blakely, 2002)

Sampai era reformasi sekarang, tampak bahwa sektor pertanian masih dan akan merupakan sektor penting dalam pertumbuhan ekonomi nasional. Sebagian besar penduduk Indonesia ( $>60 \%)$ tinggal di pedesaan dan lebih dari separuh penduduk tersebut menggantungkan hidupnya pada sektor pertanian. Sementara itu, kontribusi utama sektor pertanian terhadap pembangunan nasional telah berhasil secara nyata meningkatkan penyediaan bahan pangan khususnya beras, menciptakan kesempatan kerja, dan meningkatkan kesejahteraan masyarakat (Daniel, 2001)

Tingkat pendapatan masyarakat merupakan pencerminan dari tingkat kesejahteraan yang dinikmati Suatu masyarakat. Banyak faktor lain diluar tingkat pendapatan yang sangat berpengaruh terhadap tingkat kesejahteraan , faktor non ekonomi seperti pengaruh adat istiadat dalam kehidupan masyarakat, keadaan iklim dan alam sekitar dan ada tidaknya kebebasan bertindak dan mengeluarkan pendapat merupakan beberapa faktor yang akan menimbulkan perbedaan dalam tingkat kesejahteraan (Sukirno, 2006)

Bolaang Mongondow Utara merupakan salah satu kabupaten di Sulawesi Utara yang memiliki basik sektor pertanian, dimana sebagian besar masyarakat bermata pencaharian sebagai petani. Komoditi unggul kabupaten Bolaang Mongondow Utara yaitu padi.
Tabel 1. Luas Panen dan Produksi padi sawah menurut kecamatan di kabupaten Bolaang Mongondow Utara

\begin{tabular}{|c|c|c|c|}
\hline No & Kecamatan & $\begin{array}{c}\text { Luas Panen } \\
\text { (ha) }\end{array}$ & $\begin{array}{c}\text { Produksi } \\
\text { (ton) }\end{array}$ \\
\hline 1. & Sangkub & 2.417 & 13.035 \\
\hline 2. & Bintauna & 1.364 & 7.288 \\
\hline 3. & Bolang itang Timur & 353 & 1.876 \\
\hline 4. & Bolang itang Barat & 1.288 & 6.984 \\
\hline 5. & Kaidipang & 663 & 3.584 \\
\hline 6. & Pinogaluman & 1.194 & 6.461 \\
\hline & Total & 7.279 & 39.227 \\
\hline
\end{tabular}

Sumber : BPS Bolaang Mongondow Utara, 2016

Untuk menunjang usaha tani padi yang luas di Kabupaten Bolaang Mongondow Utara, Pemerintah membangun sarana produksi irigasi yaitu untuk penyediaan air yang sangat dibutuhkan oleh lahan sawah. Irigasi terbesar yang ada di Sulawesi Utara terdapat di Kecamatan Sangkub, dimana irigasi ini dapat menyediakan air bagi lahan sawah untuk dua Kecamatan yaitu Kecamatan Sangkub dan Kecamatan Bintauna.

Penduduk yang ada di Kabupaten Bolaang Mongondow Utara terdiri dari penduduk asli atau penduduk Lokal dan penduduk transmigran dari pulau Jawa, jumlah penduduk seluruhnya 75.290 jiwa.

Penduduk transmigran menempati 3 Desa dari 106 Desa yang ada di Bolaang Mongondow Utara yaitu Desa Sidodadi, Pangkusa dan Desa Goyo, dimana dua Desa tarmasuk pada Kecamatan Sangkub yaitu Desa Sidodadi dan Desa Pangkusa.

\begin{tabular}{|c|c|c|c|c|}
\hline & $\begin{array}{l}\text { Jawa } \\
\text { Utara }\end{array}$ & i Bolaan & $\mathbf{M}$ & gondow \\
\hline Desa & $\begin{array}{c}\text { Jumlah } \\
\text { kk }\end{array}$ & Perempuan & $\begin{array}{l}\text { Laki } \\
\text {-laki }\end{array}$ & $\begin{array}{c}\text { Jumlah } \\
\text { jiwa }\end{array}$ \\
\hline Goyo & 132 & 355 & 268 & 623 \\
\hline Sidodadi & 147 & 396 & 389 & 785 \\
\hline Pangkusa & 297 & 685 & 642 & 1327 \\
\hline
\end{tabular}

Sumber : kantor Pertanian Kecamatan Sangkub 
Walaupun dengan mata pencaharian utama yang sama yaitu bertani padi dan juga menggunakan sarana produksi irigasi yang sama, tetapi jika dilihat secara kasat mata terdapat perbedaan perkembangan antara dua Desa yang penduduknya berbeda etnis, perkembangan yang nampak yaitu kesanggupan membeli lahan dimana petani yang berasal dari etnis Non Lokal membeli lahan dengan harga yang lebih tinggi dibandingkan petani etnis Lokal, sehingga seringkali petani etnis Lokal menjual lahan mereka kepada petani-petani Non Lokal.

Perbedaan ini disebabkan oleh tingkat pendapatan petani yang berbeda yang diduga karena adanya perbedaan perspektif dalam cara budidaya sehingga produksi berbeda, mengkonsumsi sampai gaya hidup petani yang dipengaruhi oleh kebuyaan atau etnis petani. Dengan adanya masalah tersebut mendorong penulis untuk meneliti apakah faktor budaya benar mempengaruhi gaya hidup, budidaya sampai pendapatan pada petani dalam dua Desa berbeda dengan satu Kecamatan.

\section{Rumusan Masalah}

Berdasarkan uraian latar belakang yang dikemukakan, maka rumusan masalah dalam penelitian ini adalah apakah ada perbedaan pendapatan pada petani padi sawah antara etnis Lokal dan Non Lokal di Kecamatan Sangkub, Kabupaten Bolaang Mongondow Utara.

\section{Tujuan Penelitian}

Tujuan dari penelitian ini yaitu untuk melihat perbedaan pendapatan petani padi sawah antara etnis Lokal dan Non Lokal di daerah irigasi Sangkub, Kabupaten Bolaang Mongondow Utara

\footnotetext{
Manfaat Penelitian

Bagi peneliti lebih menambah pengetahuan tentang adanya perbedaan pendapatan petani yang disebabkan oleh perbedaan etnis, dan penelitian ini merupakan salah satu syarat untuk memperoleh gelar sarjana di fakultas pertanian, universitas sam ratulangi manado.

Bagi peneliti lain yaitu sebagai bahan informasi, referensi, maupun literatur untuk penelitian lebih lanjut
}

\section{METODOLOGI PENELITIAN}

Waktu dan Tempat Penelitian

Penelitian ini bertempat di Desa Sangkub Dua dan Desa Pangkusa, Kecamatan Sangkub, Kabupaten Bolaang Mongondow Utara. Dengan waktu penelitian dari bulan September 2016 sampai Desember 2016 dimulai dari pengumpulan data sampai dengan penyusunan laporan hasil penelitian.

\section{Metode Pengumpulan Data}

Jenis data penelitian yaitu data Primer dan Sekunder. Data primer diperoleh melalui wawancara langsung menggunakan daftar pertanyaan (kuisioner) dengan 40 responden petani dari dua etnis yang berbeda yaitu etnis Lokal dan Non Lokal di Kecamatan Sangkub, dan data sekunder diperoleh dari instansi-instansi terkait dengan penelitian yaitu Dinas Pertanian Kabupaten Bolmong Utara.

\section{Metode Pengambilan Sampel}

Dalam penelitian ini terdapat dua populasi yaitu petani etnis Lokal atau petani penduduk asli Bolmong dan petani Non Lokal yaitu petani etnis Jawa. Diambil 40 sampel petani, 20 dari etnis Lokal dan 20 dari etnis Non Lokal dengan menggunakan metode Simple Random Sampling (sampel acak sederhana), sampel di ambil secara acak.

\section{Konsep Pengukuran Variabel}

Adapun variabel-variabel yang diukur dalam penelitian ini adalah sebagai berikut:

1. Karakteristik petani :
a. Umur (tahun)
b. Tingkat pendidikan (SD, SMP, SMA, Perguruan Tinggi)
c. Jumlah Tanggungan Kepala Keluarga (orang)
d. Lamanya Berusahatani Padi Sawah (tahun)
e. Luas lahan yaitu luas tanam yang ditanami petani padi (ha)
f. Status Penguasaan Lahan

2. Pengeluaran yaitu biaya yang dikeluarkan oleh petani
a. Biaya tetap : pajak (Rp/thn) dan penyusutan alat $(\mathrm{Rp})$
b. biaya Variabel : benih (Rp), pupuk (Rp), pestisida (Rp), tenaga kerja (Hok)

3. Pendapatan $(\mathrm{Rp})$ 


\section{Metode Analisis Data}

Analisis data yang digunakan dalam penelitian ini adalah :

1. Analisis Pendapatan Usahatani.

a. Biaya Produksi ( total cost)

$\mathrm{TC}=\mathrm{FC}+\mathrm{VC}$

Dimana :

$\mathrm{TC}=$ Total Cost (total biaya)

$\mathrm{FC}=$ fixed cost (biaya tetap)

$\mathrm{VC}=$ variable cost (biaya tidak tetap)

b. Penerimaan (Total Revenue) $\mathrm{TR}=\mathrm{TP} \times \mathrm{P}$

Dimana :

$\mathrm{TR}=$ total revenue (penerimaan)

$\mathrm{TP}=$ total production (jumlah produksi)

$\mathrm{P}=$ price (harga jual)

c. Pendapatan petani (income)

$$
\mathrm{I}=\mathrm{TR}-\mathrm{TC}
$$

Dimana ;

I : Pendapatan

TR :Total Revenue (total penerimaan)

TC :Total Cost (total biaya)

2. Penelitian ini bersifat Kuantitatif dan Berskala interval serta bertujuan untuk membandingkan kondisi antara dua kelompok sehingga analisis statistik yang digunakan adalah Analisis Uji beda rata-rata dengan menggunakan Uji-t dua variable bebas :

$$
t=\frac{\bar{x}_{1}-\bar{x}_{2}}{\sqrt{\frac{s_{1}{ }^{2}}{n_{1}}+\frac{s_{2}{ }^{2}}{n_{2}}-2 r\left(\frac{s_{1}}{\sqrt{n_{1}}}\right)\left(\frac{s_{2}}{\sqrt{n_{2}}}\right)}}
$$

dimana $: \mathrm{r}=$ nilai korelasi $\mathrm{x}_{1}$ dengan $\mathrm{x}_{2}$

$\mathrm{n}=$ jumlah sampel

$\mathrm{x}=$ rata-rata sampel ke 1

$\mathrm{x}=$ rata-rata sampel ke 2

$\mathrm{s}_{1}=$ standar deviasi sampel ke 1

$\mathrm{s}_{2}=$ standar deviasi sampel ke 2

$\mathrm{S}_{1}=$ varians sampel ke 1

$\mathrm{S}_{2}=$ varians sampel ke 2

Dengan Hipotesis :

a. Hipotesis (Ho) diterima jika nilai sig. (2tailed) $>0,05$ berarti bahwa tidak terdapat perbedaan pendapatan pada Petani Etnis

Lokal dan Non Lokal

b. Hipotesis $\left(\mathrm{H}_{1}\right)$ diterima jika nilai sig. (2tailed) $<0,05$ berarti bahwa

terdapat perbedaan pendapatan pada petani Etnis Lokal dan Non Lokal

\section{HASIL DAN PEMBAHASAN}

\section{Deskripsi Lokasi Penelitian}

\section{Keadaan Geografis}

Desa Sangkub Dua dan Desa Pangkusa berada di Kecamatan Sangkub merupakan salah Satu Kecamatan yang ada di Kabupaten Bolaang Mongondow Utara, yang mempunyai batas-batas wilayah sebagai berikut :
a. Sebelah Utara dengan Laut Sulawesi
b. Sebelah Timur dengan Kecamatan Maelang
c. Sebelah Selatan dengan Hutan Negara
d. Sebelah Barat dengan dengan Kecamatan Bintauna

\section{Penduduk}

Jumlah penduduk yang ada di Kecamatan Sangkub yaitu 4.829 jiwa laki-laki dan 4.658 jiwa perempuan, total 9.487 jiwa dengan jumlah kepala keluarga 2.505. Penduduk yang ada di Kecamatan Sangkub terdiri dari penduduk Asli Bolaang Mongondow Utara atau penduduk Lokal dan penduduk transmigran dari Pulau Jawa. Penduduk Lokal awalnya orang-orang yang datang dari Gorontalo dan Bugis, beranak cucu dan membentuk budaya sendiri, Pada tahun 1980an pemerintah melakukan program transmigran, mendatangkan beberapa penduduk dari pulau Jawa, seiring berjalannya waktu penduduk transmigran Jawa semakin banyak, yang pertama hanya menempati satu desa, sekarang telah ada 3 desa penduduk transmigran Jawa.

\section{Karakteristik Responden}

\section{Umur}

Umur akan mempengaruhi produktifitas dalam bekerja dan dalam proses pengambilan keputusan diberbagai pekerjaan yang dilakukan. Menurut hasil penelitian yang dilakukan di Kecamatan Sangkub, umur responden dapat dilihat pada Tabel 3.

Tabel 3 menunjukan jumlah responden petani etnis Lokal dimana responden berumur 4150 tahun berjumlah 7 orang dengan persentase sebesar 35\% sama dengan jumlah responden berumur lebih dari 50 tahun yaitu berjumlah 7 orang atau persentase $35 \%$, sedangkan jumlah responden berumur kurang dari 30 berjumlah 3 orang dengan persentase $15 \%$, juga sama dengan jumlah responden berumur 31-40 tahun yaitu berjumlah 3 orang dengan persentase $15 \%$ juga. 
Untuk petani etnis Jawa, jumlah responden yang berusia lebih dari 50 tahun paling banyak yaitu 10 responden atau 50\% dari total responden. Selanjutnya pada umur 31-40 tahun berjumlah 5 orang atau persentase $25 \%$ sama dengan jumlah responden umur 41-50 tahun yaitu berjumlah 5 orang dengan persentase $25 \%$.

\section{Tingkat Pendidikan}

Peran pendidikan formal sangat penting dalam usaha peningkatan kualitas penduduk serta peningkatan intelektual serta wawasan seseorang. Berdasarkan hasil penelitian, tingkat pendidikan responden sangat bervariasi. Hal tersebut dapat dilihat pada Tabel 4.

Pada Tabel 4 menunjukan tingkat pendidikan responden petani etnis lokal dimana responden terbanyak yaitu SD berjumlah 10 orang dengan persentase 50\%, kemudian SLTA berjumlah 6 orang persentase $30 \%$, dan terakhir SLTP berjumlah 4 orang dengan persentase $20 \%$.

Sedangkan Untuk etnis Jawa dimana jumlah responden terbanyak yaitu SD berjumlah 10 responden dengan persentase 50\%, SLTA berjumlah 5 orang persentase $25 \%$, kemudian SLTP berjumlah 4 orang dengan persentase $20 \%$, dan S1 berjumlah 1 orang dengan persentase $5 \%$.

\section{Jumlah Anggota Keluarga}

Secara umum, semakin banyak anggota keluarga maka semakin besar jumlah tanggungan yang ditanggung oleh kepala keluarga. Berikut jumlah anggota keluarga dari responden yang merupakan jumlah tanggungan dari kepala keluarga, dapat dilihat pada tabel 5.

Tabel 5 menunjukkan bahwa pada petani etnis Lokal jumlah anggota terbanyak yaitu 3-5 anggota keluarga dengan jumlah responden sebanyak 17 orang persentase $85 \%$, kemudian jumlah anggota kurang dari 3 orang sebanyak 3 responden persentase $15 \%$. Sedangkan hasil untuk petani etnis Jawa dimana jumlah anggota keluarga terbanyak yaitu kurang dari 3 orang dengan jumlah responden 13 responden, persentase $65 \%$ melebihi setengah, kemudian jumlah anggota keluarga 3-5 orang dengan responden sebanyak 6 orang persentase $30 \%$ dan terakhir jumlah anggota lebih dari 5 orang yaitu berjumlah 1 orang responden dengan persentase terendah $5 \%$.

\section{Lamanya Berusahatani}

Cara berusaha tani seseorang sebagian besar dipengaruhi oleh lamanya mereka berusahatani, karena semakin lama mereka melakukan usahatani tersebut semakin dalam pengetahuannya serta semakin luas wawasan petani terhadap usahatani yang dijalankan. Tabel 6 menunjukkan jumlah Responden menurut lamanya pengalaman bekerja.

Tabel 6 menunjukkan tingkat lamanya berusahatani petani etnis Lokal dimana paling banyak pada 1-10 tahun berjumlah 6 responden (40\%), sama banyak dengan jumlah responden pada 11-20, kemudian 31-40 tahun sebanyak 4 responden (20\%), 21-30 tahun sebanyak 3 responden (15\%) dan terakhir 41-50 tahun sebanyak 1 orang responden (5\%).

Sedangkan hasil untuk petani etnis Jawa paling banyak responden pada 11-20 tahun yaitu berjumlah 8 orang responden $(40 \%)$, kemudian 21-30 tahun sebanyak 6 orang responden (30\%), untuk 31-40 tahun berjumlah 5 orang responden (25\%) dan terakhir 51-60 tahun sebanyak 1 responden $(5 \%)$.

\section{Luas Lahan}

Secara umum luas lahan sangat mempengaruhi jumlah produksi yang akan dihasilkan dengan begitu juga mempengaruhi pendapatan petani. Menurut hasil penelitian luas lahan responden dapat dilihat pada Tabel 7

Tabel 7 menunjukkan bahwa lahan yang digunakan petani Lokal sangat bervariasi, mulai dari 1 ha sampai 3 ha tidak jauh berbeda jumlah petaninya sedangkan untuk petani Non Lokal, luas lahan yang digunakan paling banyak 0,1 sampai 1 ha, yang memiliki luas lahan besar hanya beberapa petani saja.

\section{Status Penguasaan Lahan}

Penting untuk diketahui tentang status penguasaan lahan, karena saat ini banyak petani yang sudah tidak memiliki lahan sendiri karena telah dijual sehingga menyewa lahan orang lain untuk diusahakan. Status penguasaan lahan juga mempengaruhi pendapatan karena ada yang harus membayar biaya sewa diusahakan. Dapat dilihat pada Tabel 8 .

Tabel 8 menunjukkan bahwa $60 \%$ petani Lokal mengusahakan lahan sewa dan $95 \%$ petani Non Lokal mengusahakan lahan milik sendiri, hal tersebut terjadi karena petani-petani Lokal menjual lahan mereka pada petani Non Lokal, sehingga semakin sedikit petani Lokal yang mempunyai lahan sendiri untuk diusahakan. Status penguasaan lahan sangat mempengaruhi pendapatan petani karena mereka harus mengeluarkan biaya yang cukup besar untuk menyewa lahan. 
Tabel 3. Jumlah Responden Menurut Tingkat Umur

\begin{tabular}{llcccc}
\hline No & Umur (Tahun) & \multicolumn{2}{c}{ Jumlah Responden (Orang) } & \multicolumn{2}{c}{ Persentase (\%) } \\
\cline { 3 - 6 } & & Lokal & Non Lokal & Lokal & Non Lokal \\
\hline 1 & Kurang dari 30 & 3 & - & 15 & - \\
2 & $31-40$ & 3 & 5 & 15 & 25 \\
3 & $41-50$ & 7 & 5 & 35 & 25 \\
4 & Lebih dari 50 & 7 & 10 & 35 & 50 \\
\hline & Jumlah & 20 & 20 & 100 & 100 \\
\hline
\end{tabular}

Sumber : Diolah dari data primer, 2016

Tabel 4. Jumlah Responden Menurut Tingkat Pendidikan

\begin{tabular}{llcccc}
\hline No & Tingkat Pendidikan & \multicolumn{2}{c}{ Jumlah Responden (Orang) } & \multicolumn{2}{c}{ Persentase (\%) } \\
\cline { 3 - 6 } & & Lokal & Non Lokal & Lokal & Non Lokal \\
\hline 1 & SD & 10 & 10 & 50 & 50 \\
2 & SLTP & 4 & 4 & 20 & 20 \\
3 & SLTA & 6 & 5 & 30 & 25 \\
4 & S1 & - & 1 & - & 5 \\
\hline & Jumlah & 20 & 20 & 100 & 100 \\
\hline
\end{tabular}

Sumber : Diolah dari data primer, 2016

Tabel 5. Jumlah Responden Menurut Jumlah Anggota Keluarga

\begin{tabular}{llcccc}
\hline \multirow{2}{*}{\begin{tabular}{c} 
No \\
\cline { 3 - 6 }
\end{tabular}} & \multicolumn{1}{c}{$\begin{array}{c}\text { Jumlah Anggota } \\
\text { Keluarga }\end{array}$} & \multicolumn{2}{c}{ Jumlah Responden (Orang) } & \multicolumn{2}{c}{ Persentase (\%) } \\
\cline { 3 - 6 } & & Lokal & Non Lokal & Lokal & Non Lokal \\
\hline 1 & Kurang dari 3 & 3 & 13 & 15 & 65 \\
2 & $3-5$ & 17 & 6 & 85 & 30 \\
3 & Lebih Dari 5 & - & 1 & - & 5 \\
\hline & Jumlah & 20 & 20 & 100 & 100 \\
\hline
\end{tabular}

Sumber : Diolah dari data primer, 2016

Tabel 6. Jumlah Responden Menurut Pengalaman BerusahaTani (Tahun)

\begin{tabular}{cccccc}
\hline No & Lamanya Berusahatani & \multicolumn{2}{c}{ Jumlah Responden (Orang) } & \multicolumn{2}{c}{ Persentase (\%) } \\
\cline { 3 - 6 } & & Lokal & Non Lokal & Lokal & Non Lokal \\
\cline { 3 - 6 } & $1-10$ & 6 & - & 30 & - \\
2 & $11-20$ & 6 & 8 & 30 & 40 \\
3 & $21-30$ & 3 & 6 & 15 & 30 \\
4 & $31-40$ & 4 & 5 & 20 & 25 \\
5 & $41-50$ & 1 & - & 5 & - \\
6 & $51-60$ & - & 1 & - & 5 \\
\hline & Jumlah & 20 & 20 & 100 & 100 \\
\hline
\end{tabular}

Sumber : Diolah dari data primer, 2016 
Tabel 7. Jumlah Responden Menurut Luas Lahan yang Diusahakan

\begin{tabular}{cccccc}
\hline No & Luas Lahan (Ha) & \multicolumn{2}{c}{ Jumlah Responden (Orang) } & \multicolumn{2}{c}{ Persentase (\%) } \\
\cline { 3 - 6 } & & Lokal & Non Lokal & Lokal & Non Lokal \\
\hline 1 & $0,1-1,0$ & 9 & 16 & 45 & 80 \\
2 & $1,1-2,0$ & 7 & 2 & 35 & 10 \\
3 & $2,1-3,0$ & 3 & 1 & 15 & 5 \\
4 & $3,1-4,0$ & 1 & 1 & 5 & 5 \\
& & & & & 100 \\
\hline
\end{tabular}

Sumber : Diolah dari data Primer, 2016

Tebel 8. Jumlah responden Menurut Status Penguasaan Lahan

\begin{tabular}{|c|c|c|c|c|c|}
\hline \multirow[t]{2}{*}{ No } & \multirow{2}{*}{$\begin{array}{c}\text { Status Penguasaan } \\
\text { Lahan }\end{array}$} & \multicolumn{2}{|c|}{ Jumlah Responden (Orang) } & \multicolumn{2}{|c|}{ Persentase $(\%)$} \\
\hline & & Lokal & Non Lokal & Lokal & Non Lokal \\
\hline 1 & Milik Sendiri & 8 & 19 & 40 & 95 \\
\hline 2 & Lahan Sewa & 12 & 1 & 60 & 5 \\
\hline & Jumlah & 20 & 20 & 100 & 100 \\
\hline
\end{tabular}

Sumber : Diolah dari data Primer, 2016

\section{Produksi, Biaya Produksi, Penerimaan dan Pendapatan per Hektar}

Biaya produksi adalah keseluruhan biaya yang digunakan dalam satu kali proses produksi. Biaya produksi meliputi biaya tetap yaitu biaya pajak, biaya penyusutan alat, sewa lahan. Dan biaya tidak tetap yaitu benih, pupuk, bahan bakar, pestisida, herbisida, dan biaya tenaga kerja. Ratarata biaya produksi petani dari hasil penelitian dapat dilihat pada Tabel 9.

Tabel 9 menunjukkan jumlah benih yang digunakan tidak jauh berbeda, rata-rata dalam 1 ha petani Lokal maupun Non Lokal menggunakan ukuran 3 kaleng benih dengan harga Rp.60.000 per kaleng. Biaya pengolahan lahan untuk sewa traktor paling tinggi dikeluarkan oleh petani Lokal selisih Rp.306.250, jumlah yang cukup besar, diakibatkan oleh kepemilikan traktor dimana petani Non Lokal rata-rata memiliki traktor sendiri sedangkan petani Lokal menyewa, jadi biaya yang dikeluarkan petani Non Lokal paling banyak di bahan bakar. Selanjutanya biaya pemupukan paling tinggi oleh petani Non Lokal, Petani Lokal hanya akan memberika pupuk serta pestisida ketika ada bantuan pupuk dan pestisida dari pemerintah, berbeda dengan petani Non
Lokal yang tidak bergantung pada bantuan, petani Non Lokal juga memberikan pemupukan dua kali agar produksi meningkat.

Biaya tenaga kerja tidak jauh berbeda, biaya sewa buruh tani untuk petani Lokal maupun Non Lokal sama yaitu Rp.75.000 per hari, Yang berbeda hanya jumlah buruh yang di sewa, petani Lokal rata-rata 5-6 orang dan untuk petani Non Lokal 8-10 orang per Ha. Sewa tenaga kerja untuk panen menggunakan sistim bagi hasil 5:1, karena jumlah produksi per Ha petani Non Lokal lebih tinggi dari petani Lokal sehingga jumlah biaya panen serta sewa gilingan petani Non Lokal juga lebih tinggi.

Tabel 10 menunjukkan rata-rata produksi, biaya produksi, penerimaan dan pendapatan per hektar petani Non Lokal lebih tinggi dibandingkan dengan petani Lokal. Hampir semua petani Lokal menyewa lahan yang digunakan, dengan sistim sewa bagi hasil 3:1, namun jumlah Produksi yang dimasukkan di tabel adalah produksi bersih, tidak dikurangi dengan sewa lahan. Begitu juga dengan jumlah pendapatan tidak dikurangi dengan biaya sewa lahan untuk melihat efisiensinya. 
Tabel 9. Rata-rata Biaya Produksi Per Hektar

\begin{tabular}{|c|c|c|c|}
\hline No & Jenis Biaya & Lokal (Rp) & Non Lokal (Rp) \\
\hline 1. & Benih & 180.500 & 180.000 \\
\hline \multirow[t]{3}{*}{2.} & Pengolahan Lahan : & & \\
\hline & Sewa Traktor & 1.037 .500 & 731.250 \\
\hline & Bahan Bakar & 241.400 & 303.917 \\
\hline \multirow[t]{5}{*}{3.} & Pupuk : & & \\
\hline & Urea & 211.359 & 247.982 \\
\hline & NPK & 250.625 & 202.969 \\
\hline & TSP & - & 125.000 \\
\hline & Phonska & 223.750 & 320.000 \\
\hline 4. & Pestisida & 231.367 & 289.479 \\
\hline \multirow[t]{2}{*}{5.} & Pemeliharaan : & & \\
\hline & Herbisida & 208.200 & 272.039 \\
\hline \multirow[t]{4}{*}{6.} & Tenaga Kerja : & & \\
\hline & Pengolahan Lahan & 77.875 & 117.500 \\
\hline & Penanaman & 589.315 & 697.290 \\
\hline & Panen & 3.189 .465 & 3.997 .965 \\
\hline \multirow[t]{2}{*}{7.} & Sewa Gilingan & 1.582 .900 & 2.270 .650 \\
\hline & Total & 8.024 .256 & 9.756 .041 \\
\hline
\end{tabular}

Sumber : Diolah dari data primer, 2016

Tabel 10. Rata-rata Produksi, Biaya Produksi, Penerimaan Dan Pendapatan per Hektar

\begin{tabular}{lccccc}
\hline \multicolumn{1}{c}{ Petani } & $\begin{array}{c}\text { Produksi } \\
(\mathrm{kg})\end{array}$ & $\begin{array}{c}\text { Harga } \\
(\mathrm{Rp})\end{array}$ & $\begin{array}{c}\text { Penerimaan } \\
(\mathrm{Rp})\end{array}$ & $\begin{array}{c}\text { Biaya produksi } \\
(\mathrm{Rp})\end{array}$ & $\begin{array}{c}\text { Pendapatan } \\
(\mathrm{Rp})\end{array}$ \\
\hline Etnis Lokal & 1978 & 8000 & 15.828 .800 & 6.795 .088 & 9.033 .712 \\
Etnis Non Lokal & 2838 & 8000 & 22.706 .400 & 8.615 .687 & 14.090 .713 \\
\hline
\end{tabular}

Sumber : Diolah dari data primer, 2016

\section{Uji Beda Rata-rata}

Untuk membandingkan pendapatan petani padi sawah menggunakan analisis Uji Beda Rata-rata dengan menggunakan Uji-t dua variabel bebas (independen). Dalam penelitian ini perhitungan uji beda rata-rata menggunakan aplikasi SPSS, Dengan kriteria keputusan :

Nilai sig (2-tailed) > 0,05: $\mathrm{H}_{0}$ diterima dan $\mathrm{H}_{\mathrm{a}}$ ditolak

Nilai sig (2-tailed) $<0,05: \mathrm{H}_{\mathrm{a}}$ diterima dan $\mathrm{H}_{0}$ ditolak

\section{Uji beda Rata-rata Produksi per hektar}

Berdasarkan hasil analisis program SPSS pada lampiran 9 diperoleh nilai $\mathrm{t}-3.249$, nilai sig 0,002 < 0,05 maka Ho ditolak dan Ha diterima, artinya terdapat perbedaan produksi pada petani etnis Lokal dan etnis Non Lokal.

\section{Uji beda Rata-rata Biaya Produksi per hektar}

Berdasarkan hasil analisis program SPSS pada lampiran 9 diperoleh nilai $\mathrm{t}-2.566$, nilai sig 0,014 < 0,05 maka Ho ditolak dan Ha diterima, artinya terdapat perbedaan biaya produksi pada petani etnis Lokal dan etnis Non Lokal.

\section{Uji beda rata-rata Pendapatan per hektar}

Berdasarkan hasil analisis program SPSS pada lampiran 9 diperoleh nilai $\mathrm{t}-3.167$, nilai sig $0,003<0,05$ maka Ho ditolak dan Ha diterima, artinya terdapat perbedaan pendapatan pada petani etnis Lokal dan etnis Non Lokal. 


\section{Hasil Penelitian Berdasarkan Teori}

Hasil penelitian menunjukkan bahwa terdapat perbedaan pendapatan antara petani Lokal dan Non Lokal (Jawa) di daerah Irigasi Sangkub. Pendapatan petani Non Lokal lebih tinggi dibandingkan dengan pendapatan petani Lokal. Terdapat banyak perbedaan dalam hal etos kerja, jam kerja serta, perilaku bekerja petani, menurut Sukirno (2006) kebudayaan atau adat istiadat merupakan factor non ekonomi yang berpengaruh pada pola perilaku dalam berusaha sehingga mempengaruhi produktivitas dan pendapatan.

Menurut Palilati (2015) dalam kegiatan keseharian sangat sedikit orang-orang Jawa ditemukan siang hari berada di rumah , kebanyakan dari mereka telah meninggalkan rumah diwaktu subuh untuk pergi ke ladang dan kembali ke rumah pada waktu sore hari menjelang maghrib, dalam penelitian sangat susah untuk bertemu dengan petani Non Lokal (Jawa) karena subuh mereka telah pergi ke ladang dan kembali kerumah di atas jam 6 sore. Berbeda dengan petani Lokal dimana mereka berangkat ke ladang jam 7 pagi dan kembali sebelum jam 4 sore.

Perbedaan pendapatan disebabkan oleh jumlah produksi yang berbeda, menurut Rejeki (2015) mata pencaharian paling dominan pada masyarakat etnik Jawa adalah bertani, Budidaya padi tidak hanya penting bagi ekonomi, melainkan berkaitan dengan kebudayaan.

Petani Non Lokal (Jawa) sangat memperhatikan proses budidaya yang dilakukan, dapat dilihat pada biaya produksi yang dikeluarkan pada table 9, yang pertama biaya produksi pemeliharaan atau penggunaan herbisida untuk menghilangkan gulma yang dapat menghambat pertumbuhan tanaman lebih tinggi dikeluarkan oleh petani Non Lokal, kedua biaya produksi untuk Pupuk dan pestisida yang dikeluarkan petani Non Lokal sangat jauh lebih tinggi dan terakhir sarana yang digunakan, petani Non Lokal sudah memiliki traktor sendiri sehingga biaya pengolahan lahan yang dikeluarkan petani Lokal sangat tinggi yaitu untuk biaya sewa traktor

\section{KESIMPULAN DAN SARAN}

\section{Kesimpulan}

Pendapatan petani padi sawah antara etnis Lokal dan Non Lokal berbeda. Walaupun dalam luas lahan yang sama dengan jumlah benih yang sama namun jumlah produksi petani non lokal lebih tinggi dari produksi lokal. Etnis mempengaruhi cara, perilaku, motivasi dan jam kerja petani dalam berusaha tani. Biaya produksi yang dikeluarkan petani lokal untuk usaha tani jauh lebih tinggi dibandingkan jumlah biaya produksi yang dikeluarkan petani lokal, khususnya biaya produksi untuk pupuk dan pestisida yang jauh berbeda.

\section{Saran}

Untuk petani lokal sebaiknya memperhatikan pemberian pupuk dan pestisida, karena sangat berpengaruh terhadap jumlah produksi yang akan dihasilkan. Semangat, keseriusan, jam kerja dan motivasi bekerja lebih ditingkatkan.

\section{DAFTAR PUSTAKA}

azwir dan ridwan, 2009. peningkatan produktifitas padi sawah dengan perbaikan teknologi budidaya. Jurnal balai Pengkajian Teknologi Petanian Sumatera Barat.

Badan Pusat Statistik kabupaten Bolaang mongondow Utara dalam angka 2015

Daniel, M. 2001. Pengantar Ekonomi Pertanian. Medan: Bumi Aksara

Kaunang, A. 2014. Perbandingan Pendapatan Petani Pala Pada berbagai saluran pemasaran di kecamatan Kauditan di Kabupaten Minahasa Utara. Fakultas Pertanian Universitas Sam Ratulangi Manado.

Lumintang,F.2013. analisis pendapatan petani padi di desa teep kecamatan langowan timur, Fakultas Ekonomi dan bisnis Universitas Sam Ratulangi Manado 
Nurani L, Hallidah dan Tabba S, 2015. Pengaruh Etnis Terhadap Pola Pemanfaatan Lahan Dan Kontribusinya Bagi Pendapatan Masyarakat Di Taman Nasional Aketajawe Lolobata.

Panggalo, F. 2013. Perilaku komunikasi antarbudaya Etnik Toraja dan Etnik Bugis Makassar di Kota Makasar. Fakultas ilmu sosial Dan ilmu politik Universitas Hasanuddin

Rahman, A. 2013. Analisis Pendapatan Usahatani Padi Sawah Pada Sistem Tanam Legowo diKecamatan Dungaliyo Kabupaten Gorontalo. Fakultas Ilmu-ilmu Pertanian Universitas Negeri Gorontalo.

Rahardja, P \& Manurung, M. 2002. Pengantar Ilmu Ekonomi (makroekonomi \& mikroekonomi). Edisi ketiga. Jakarta: Fakultas Ekonomi Universitas Indonesia.

Rejeki, S. 2015. Etnik Jawa (studi sejarah sosial di kotaraya, kab. Parigi Moutong). Fakultas ilmu sosial Universitas Negeri Gorontalo.
Sukirno, Sadono. 2000. Mikro Ekonomi Modern: Perkembangan Pemikiran dari klasik sampai Keynesian Baru, Edisi 1. PT Raja Grafindo, Jakarta

Soekartawi. 2002. Analisis Usahatani. Penerbit Universitas Indonesia (UI- Press), Jakarta

Sukirno, S. 2010. Ekonomi Pembangunan. Edisi kedua. Jakarta: Kencana Prenada Media Group.

Todaro, M. 1995. Ekonomi Untuk Negara Berkembang. Edisi ketiga. Jakarta: Bumi Aksara.

Todaro, M \& Smith, S. 2006. Pembangunan Ekonomi. Edisi kesembilan. Jakarta: Penerbit Erlangga. 